\title{
Microwave heating enhanced distillation and concentration of sulfuric acid under vacuum
}

\author{
shihong $\operatorname{Tian}^{1}$, Lei Guo ${ }^{1}$, Lei Xu ${ }^{1}$, Libo Zhang ${ }^{1}$, shaohua $\mathrm{Ju}^{1}$, and Chunqiang $\mathrm{Lu}^{1}$ \\ ${ }^{1}$ Kunming University of Science and Technology - Lianhua Campus
}

June 26, 2020

\begin{abstract}
A novel microwave heating flash evaporation system (MWHFES) was carried out to concentrate and distillate sulfuric acid, and this system may overcome the problems that equipment corrosion, product pollution, high energy consumption, long process and lower heat transfer rate in waste sulfuric acid recycle though purification and concentration. The dilute sulfuric acid with mass fraction of $75 \mathrm{wt} \%$ was used as experimental material, 5 experimental cases was generated to verify the effect of MWHFES under the conditions of different volume, microwave power and depressurization rate. Results shown that the sulfuric acid could be concentrated to mass fraction of $85-95 \%$, and the heating efficiency was among $30 \%$ to $80 \%$, heat transfer volume coefficient was among 100 to 500 though the combination of vacuum and microwave heating. Thermal process analysis indicated that the interaction among experimental factors had effect on distillation process. At last, the process optimization and selection were explained briefly.
\end{abstract}

\section{Hosted file}

manuscript.docx available at https://authorea.com/users/337228/articles/462833-microwaveheating-enhanced-distillation-and-concentration-of-sulfuric-acid-under-vacuum 